- ACORN Australan college of | JOURNAL OF PERIOPERATIVE NURSING

Volume 29 | Issue 4

Article 2

12-1-2016

\title{
A personal perspective on separating families before surgery
}

Follow this and additional works at: https://www.journal.acorn.org.au/jpn

Part of the Health Services Administration Commons, Health Services Research Commons, Perioperative, Operating Room and Surgical Nursing Commons, and the Surgery Commons

(c) (i)

This work is licensed under a Creative Commons Attribution 4.0 License.

\section{Recommended Citation}

Steward, Coralie (2016) "A personal perspective on separating families before surgery," Journal of Perioperative Nursing: Vol. 29 : Iss. 4 , Article 2.

Available at: https://doi.org/10.26550/2209-1092.1009

https://www.journal.acorn.org.au/jpn/vol29/iss4/2

This Article is brought to you for free and open access by Journal of Perioperative Nursing. It has been accepted for inclusion in Journal of Perioperative Nursing by an authorized editor of Journal of Perioperative Nursing. 


\section{A personal perspective on separating families before surgery}

\author{
Once in a while, something happens to us that makes us question \\ our faith in the caring ethos which is so integral to our role as \\ clinicians.
}

I have spent most of my 30-year career working in operating theatres as a Clinical Nurse and Nurse Manager. I like to think that during all of those years I have actively advocated for the patient's needs and facilitated, wherever possible, the involvement of and care for the patient's family. Reassurance, compassion and support for the family as well as the patient was not something I ever questioned, I always just assumed that this was part of holistic patient care. It therefore came as quite a shock - in fact, a profound disillusionment - to realise that in today's enlightened world of patient-centred care there are still practices that fly in the face of everything that, as a profession, we supposedly hold so dear.

Firstly, let's set the scene with an elderly male patient, who may be scared and anxious, awaiting major surgery for the first time. This patient is awaiting a bowel resection for malignancy at a large Perth public/ private hospital but feel free to replace this with just about any patient awaiting surgery anywhere. After 30 years as a theatre nurse I can tell you that nearly everyone is anxious, whether they admit this to their family or not.

In fact, countless studies have been done to examine the incidence of preoperative anxiety. A simple Google search of scholarly articles relating to preoperative anxiety returned over 894 articles for 2015 alone. The large number of articles available on this subject, addressing the incidence, the impacts, and the effectiveness of different approaches to reducing this anxiety, confirm that preoperative anxiety is an issue worth consideration and study. Ebirim and Tobin ${ }^{1}$ in their study found that 90.4 per cent of participants admitted that they had one or more anxieties - not an insignificant number. The fact that numerous preoperative anxiety scales have been developed and are in use, e.g. the Amsterdam Preoperative Anxiety and Information Scale (APAIS) ${ }^{2}$, the Yale Preoperative Anxiety Scale [YPAS] $^{3}$ and the State-Trait Anxiety Inventory (STAI) ${ }^{4}$, is testament to the validity of preoperative anxiety as a legitimate concern.

Let's return to that scene where several hours before the surgery start time, and check in at the hospital reception. Let's also assume that, as with most mature men, this patient is reluctant to admit that he is feeling vulnerable and nervous, maybe he even says 'I'm fine, love' but inside he is quietly trepidatious. Add to that an elderly spouse who is also apprehensive and concerned about the safety of their lifelong partner. In his article, Kevin Campbell ${ }^{5}$ explores the experiences of relatives as well as patients during the preoperative waiting time and highlights that waiting, before and during surgery, places psychological stress upon loved ones as well as the patient. There is no doubt in my our patient and his family arrive,

\section{Author}

Coralie Steward

BA (Nurs), GradCert (ORNursing), GradCert (OperatingSuiteManagement)

mind that fear for the safety of the most treasured people in our life is an undeniable result of their pending surgery. I don't know if my working in that area has made the stress increase, or decrease. Some of my family are very happy to live in the 'ignorance is bliss' camp, and there are times when I wish I could join them for a few happily blissful hours but, unavoidably, all the potential risks and complications weigh heavily whether they are vocalised or not.

Back to reception where the clerical hospital admission is complete and the wheelchair arrives to transport the patient to the Day of Surgery Admission (DOSA) area before theatre. However, instead of having family members go with him and be near him, providing support until he goes to theatre as expected, only the patient is taken to an area of the hospital for check-in and preparation for theatre. He will now spend the next two to three hours alone. The family members, who are completely astounded, are told that they cannot stay with their sick loved one. They are told that they will get a phone call in about five to six hours, when the patient is back on the ward. I have to point out that the manner in which this information is delivered is polite and professional - it is the content that is the issue!

The patient in the scene I have described is my father-in-law and, therefore, I am one of those family members. My initial reaction to his being taken alone to DOSA is disbelief, then amazement, then anger. As a perioperative manager I have read numerous research papers which detail the potential results of preoperative anxiety in 
patients yet here I am, left standing in a hospital reception, watching my father-in-law being wheeled away for 'processing' where he will be alone with his thoughts for the next three hours. The words 'cattle herding' keep forming in my mind. The man disappearing round the corner is undergoing his first surgical operation which, he has been told, carries a high risk due to his underlying cardiac condition. The stress the family has been through in the preceding six weeks has been immense, with initial scans indicating a terminal prognosis. The rollercoaster of emotion from despair to hope has not been an enjoyable ride but being thrown out of the carriage and watching my father-inlaw continue the ride alone is not a scenario that I ever envisaged. I can't begin to imagine what is going through his mind for the next three hours, but I can guarantee it has a significant degree of anxiety attached to it.

Let's be objective for a minute here though. What's the big deal anyway? Am I overreacting and making a mountain out of a molehill? Well, there are hundreds of studies worldwide on the incidence, effects and management of preoperative anxiety and, at the very least, as Vaughn, Wichowski and Bosworth state in their paper, 'most of the available evidence reveals a positive correlation between preoperative anxiety and postoperative pain'6(p.589). Pritchard elaborates on this topic further: 'The levels of anxiety that a patient experiences can affect his or her response to the anaesthetic and analgesia. It may also increase pain, cause depression, nausea and fatigue, and delay healing, which can impede the patient's discharge from hospital'7(p.39). Pritchard's paper 'Identifying and assessing anxiety in pre-operative patients' is one of many which delves into the complexities of preoperative anxiety, and it highlights the current thinking that 'empowering patients and addressing their psychosocial needs can decrease the risk of complications and improve postoperative health outcomes' ${ }^{\prime(p .36)}$.

Completely aside from the anxiety issue, there is another issue which I believe is related to separating family before surgery and that is patient safety. I can envisage significant risk as a result of some patients forgetting to ask questions or not conveying important information to clinicians. In my experience, many patients under stress rely on their family to jolt their memory or ask the doctor that one final important question. In their publication, A Clinician's Handbook: Talking With Your Older Patient, the USA's National Institute of Aging says that family and informal caregivers can be extremely important 'informants' ${ }^{8(p .49)}$, and play an increasingly vital role in how the health care system functions. In many cases, a family member can be a facilitator, helping the patient express concerns and reinforcing understanding of communication from all health care professionals. I cannot recall how many times a patient's relative has told me something relevant that the patient forgot to mention or didn't reveal because they thought it 'wasn't important enough to bother the doctor'. Not allowing family to be with the patient at this crucial time may be a serious safety issue.

My emotional side just asks, 'Why would you do this to someone?' Can you ever imagine leaving your mother, or father, or husband, or wife, or best friend alone when they need you there the most? This prompts the question as to why any modern hospital would have this 'policy of separation' (as I have coined it). I decided to follow this up from home half an hour after leaving the hospital. (For those of you asking why we didn't kick up a stink at the time, the answer is, we were too emotional). I rang the hospital reception who put me through to the Consumer Liaison Service and I was told that this policy is apparently driven by the hospital's decision to admit DOSA patients via the Day Procedure Unit where, due to the physical size of the area, family members are discouraged unless their presence is absolutely unavoidable. I was told that if the patient really needs a family member with them, hospital staff would try to work something out. My question would be, which patients do not need their family around them? Who can determine who 'really' needs someone? So much history is unknown to a clerk at a reception desk, how could they ever be expected to make a judgement about the needs of an individual being admitted for an operation?

I freely admit that I burst into tears during this phone conversation. I usually consider myself a tough nut, but the thought of my father-inlaw alone in that waiting room just really got to me. I felt completely powerless. It is not only the patient who suffers here, family members are also left feeling gutted and alone and frightened.

I can see that there is a case for better utilisation of hospital beds, certainly a major financial driver for hospital management, but if patients are going to be processed before surgery in a defined area to improve bed management and efficiency then planning needs to occur to ensure that the patient and their family do not suffer being separated at such a vital time. Let me point out that I have no issue with limiting the number of accompanying family members to one if there is a physical 
restriction but to allow no one is, in my opinion, unacceptable.

Why did this separation upset me so much? Well, the way I see it is that an integral part of managing preoperative stress is identifying and implementing anxiety-reducing techniques. There are several studies which identify the use of music as relieving anxiety ${ }^{9-13}$, many detailing the value of adequate information relating to the anaesthetic and the surgery ${ }^{13,14}$, and some about administration of preoperative medication ${ }^{1,7,11}$, but the studies which get most of my attention are those about the value of distraction, attention focusing, emotional and practical support from friends and family ${ }^{5,711}$ and those about nursing support for patients with their families immediately before theatre ${ }^{15}$. I don't believe that any research can fully document the value of having someone's family around to support, distract, joke, and encourage them at this most crucial time in their life. Dr Campbell highlights this in his article, 'How families cope with the surgical waiting room'.

Unoccupied time feels longer than occupied time, anxiety makes waits seem longer, and solo waits seem longer than group waits. Having support and company in the waiting room is essential... one cannot underestimate the value of friends, family and clergy during the hours spent in the surgical waiting area.

Dr Campbell's own experiences of preoperative anxiety prompted him to highlight the importance of family support for both the patients and the waiting relatives.

When is it OK to move from patientcentred care, which incorporates facilitating family support and involvement, to 'hospital floor plan limiting' care, which actively excludes family support before surgery? Is it really all about the budget? In all the years that I have worked in theatre, I have never, in any hospital in Western Australia or interstate, seen such a policy. In my experience, most hospitals actively encourage family to stay and support their relatives. To test my theory, and perhaps justify my feeling so distressed, I researched the policies for management of relatives in DOSA Units and Day Procedure Units at six Perth hospitals similarly large in size. Without exception, they all keenly encouraged relatives to stay and support the patient. One metropolitan private hospital acknowledged that the space for relatives in their DOSA area was significantly limited so they preferred only one relative to stay but more were welcome if the family felt the need.

This prompted me to write a letter to the hospital that treated my fatherin-law. At the time of writing this article, I have received a response from the CEO apologising for the care not meeting my expectations, acknowledging that I had raised some valid concerns and informing me that they are conducting a review. There has been no response from the DOSA Unit Manager who is looking into my complaint. Apart from the complete disregard of evidencebased practice, the issue that really disturbs me is that someone (or, in fact, many people) must have actually thought that this treatment of their patients was OK in the first place. Did the hospital and nursing executive approve this policy? Do the surgeons and anaesthetists know that this is how their patients are being managed before surgery? Did the nurses call out that this was not an acceptable way to treat patients? If they did, why has nothing been done to amend the policy?

Would any of the medical or nursing staff, or hospital executive, be happy to be separated from their loved ones as either a patient or a relative in these circumstances? I'm guessing that the answer to that would be a resounding 'No'.

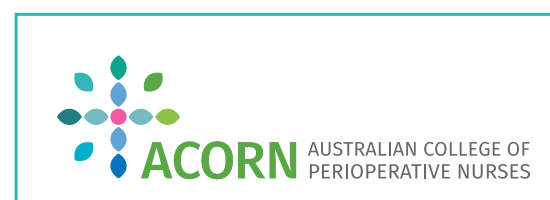

Mentoring for novice authors

All you need is an idea and ACORN will help you write for publication.

Writing a professional article may seem like a daunting task but, with ACORN's developmental editing assistance, you can do it.

Step 1: Get your idea on paper a rough draft is enough.

Step 2: Contact the

ACORN Journal Editor at journaleditor@acorn.org.au.

Step 3: Work with an ACORN editor to develop the content and structure of your article.

Step 4: Submit your article for publication.

For more information, including guidelines for preparing your manuscript, visit www.acorn.org. au/journal and select 'Submit a manuscipt' or send an email to journaleditor@acorn.org.au.

We look forward to helping you reach your publishing goals and expanding your professional experience! 


\section{References}

1. Ebirim L, Tobin M. Factors responsible for pre-operative anxiety in elective surgical patients at a university teaching hospital: A pilot study. [Internet] J Anesthesiol 2010;29:2 [cited 2015 Jun 10]. Available from: https:// ispub.com//JA/29/2/8534.

2. Boker A, Brownell L, Donen N. The Amsterdam preoperative anxiety and information scale provides a simple and reliable measure of preoperative anxiety. Can J Anaesth 2002;49(8):792-798 [cited 2015 Jun 9]. Available from: www.ncbi.nlm.nih. gov/pubmed/12374706.

3. Kain Z, Mayes L, Cicchetti D, Bagnall A, Finley J, Hofstadter $M$. The Yale preoperative anxiety scale: How does it compare with a 'gold standard'? Anesthesia \& Analgesia 1997;85(4):783-788 [cited 2015 Jun 10]. Available from: http:/ / journals. Lww.com/ anesthesia-analgesia/Fulltext/1997/10000/ The_Yale_Preoperative_Anxiety_Scale__How_ Does_It.12.aspx.

4. The state-trait anxiety inventory (STAI) [Internet]. American Psychological Association; 2015 [cited 2015 Jun 9]. Available from www.apa.org/pi/about/publications/ caregivers/practice-settings/assessment/ tools/trait-state.aspx.

5. Campbell K. How families cope with the surgical waiting room [Internet] 2012 Jun 20 [cited 2015 Jun 9]. Available from: www. kevinmd.com/blog/2012/06/families-copesurgical-waiting-room.html.
6. Vaughn $\mathrm{F}$, Wichowski $\mathrm{H}$, Bosworth $\mathrm{G}$. Does preoperative anxiety level predict postoperative pain? AORN J 2007;85(3):589604 [cited 2015 Jun 10]. Available from: www.aornjournal.org/article/S00012092(07)60130-6/abstract.

7. Pritchard M. Identifying and assessing anxiety in pre-operative patients. Nurs Stand 2009;23(51):35-40 [cited 2015 Jun 10]. Available from: http:/ / journals.reni.com/ doi/abs/10.7748/ns2009.08.23.51.35.c7222.

8. A clinician's handbook: Talking with your older patient. [Internet]. U.S. Department of Health and Human Services National Institute on Aging 2011 [cited 2015 June 13]. Available from: https://d2cauhfh6h4x0p. cloudfront.net $\overline{\text { s3fs-public/talking_with_ }}$ your_older_patient.pdf.

9. Surgery [Internet]. Institute for Quality and Efficiency in Health Care (IQWiG, Germany) 2006 [updated 2014 May 21; cited 2015 Jun 10]. Available from: www. informedhealthonline.org/what-canhelp-relieve-anxiety-before-surgery.2680, en.html? part=vorbereitung-3h.

10. Wang S, Kulkarni L, Dolev J, Kain Z. Music and preoperative anxiety: A randomized, controlled study. Anesth \& Analg 2002;94(6):1489-1494 [cited 2015 Jun 9]. Available from: http://journals.lww.com/ anesthesia-analgesia/Fulltext/2002/06000/ Music_and_Preoperative_Anxiety__A_ Randomized,.21.aspx.
11. What can help relieve anxiety before surgery? [Internet]. Institute for Quality and Efficiency in Health Care (IQWiG, Germany) [updated 2014 May 21; cited 2015 June 9]. Available from: www.ncbi.nlm.nih.gov/ pubmedhealth $\overline{\mathrm{PMHO} 072741}$

12. Arslan S, Özer N, Özyurt F. Effect of music on preoperative anxiety in men undergoing urogenital surgery. Aust J Adv Nurs 2009;26(2):46-54 [cited 2015 Jun 9]. Available from: http: / /ajan.com.au/Vol26/26-2_Ozer. pdf.

13. Cooke $M$, Chaboyer W, Schluter P, Hiratos $M$. The effect of music on preoperative anxiety in day surgery. J Adv Nurs 2005;52(1):47-55 [cited 2015 Jun 9]. Available from: www. ncbi. nlm.nih.gov/pubmed/16149980.

14. Jawaid M, Mushtaq A, Mukhtar S, Khan Z. Preoperative anxiety before elective surgery. Neurosciences 2007;12(2):145-148 [cited 2015 Jun 9]. Available from: www neurosciencesjournal.org/pdffiles/Apr07/ Preooperative.pdf.

15. Erci B, Sezgin S, Kaçmaz Z. The impact of therapeutic relationship on preoperative and postoperative patient anxiety. Aust Adv Nurs 2008;26(1):59-66 [cited 2015 Jun 10]. Available from: www.ajan.com.au/Vol26/261v2_Erci.pdf. 